\title{
PRODUÇÃO E QUALIDADE DA BATATA EM RESPOSTA AO BORO ${ }^{1}$
}

\author{
Yield and quality of the potato in response of boron levels
}

\author{
Hugo Adelande de Mesquita ${ }^{2}$, Marco Antônio Rezende Alvarenga ${ }^{3}$, Miralda Bueno de Paula ${ }^{2}$, \\ Janice Guedes de Carvalho ${ }^{3}$, Júlio César Azevedo Nóbrega ${ }^{4}$
}

\begin{abstract}
RESUMO
O trabalho foi desenvolvido com o objetivo de avaliar a produtividade e qualidade de tubérculos de batata em resposta ao boro em amostras de um Latossolo Vermelho (LV) e de um Cambissolo (CX). O delineamento experimental foi o de blocos casualizados, em esquema fatorial 4 x 2, constituído de quatro doses de boro $\left(0,0 ; 0,75 ; 1,50\right.$ e $\left.3,0 \mathrm{mg} \mathrm{dm}^{-3}\right)$ e duas cultivares de batata (Asterix e Monalisa), com três repetições. Foram avaliados a produtividade, a massa seca, teores de amido, açúcares redutores e açúcares totais dos tubérculos. As doses crescentes de boro aumentaram a produtividade principalmente para a cultivar Asterix, cultivada no LV com a dose de 2,19 $\mathrm{mg} \mathrm{dm}^{-3}$ de boro. No LV, a cultivar Asterix também apresentou maiores porcentagens de massa seca e amido nos tubérculos, enquanto os teores de açúcares redutores reduziram-se com o aumento de boro nas duas cultivares. No CX, a produtividade foi menor que no LV, provavelmente, devido ao alto teor de silte do solo que dificultou a formação dos tubérculos. A Asterix foi $108 \%$ mais produtiva e $37 \%$ mais exigente em boro, quando comparada à Monalisa.
\end{abstract}

Termos para indexação: Solanum tuberosum L, micronutrientes, massa seca, amido, açúcares.

\begin{abstract}
The experiment was carried out in a greenhouse, using two soils Latosol (LV) and Cambisol (CX) to evaluate the effects of boron rates on yield and tubers quality for two potato cultivars, Asterix and Monalisa. The experimental design was a randomized blocks in a 4 x 2 factorial arrangement with three replications, using four boron rates $\left(0.0,0.75 ; 1.50\right.$ and $\left.3.0 \mathrm{mg} \mathrm{dm}^{-3}\right)$ and two potato cultivars (Asterix and Monalisa). Two soil types were used; Latosol and Cambisol. Yield, dry matter, starch, reducing sugars and total sugars tuber contents were evaluated. Increasing boron rates improved tuber yield, reaching maximum yield on Red Latosol at $2.19 \mathrm{mg}$ $\mathrm{dm}^{-3}$ of boron. For Asterix cultivar, also presented the highest percentages of dry matter and starch in tubers on a Red Latosol. Reducing sugar content decreased with boron rates in Red Latosol. For both cultivars, in Cambisol, yield was lower than Red Latosol, due to the high silt content in Cambisol, making difficult tuber formation. Asterix cultivar presented 108\% greater yield than Monalisa in Cambisol, although requiring 37\% more boron.
\end{abstract}

Index terms: Solanum tuberosum L., micronutrient, dry matter, starch, sugars.

(Recebido em 24 de março de 2006 e aprovado em 14 de agosto de 2006)

\section{INTRODUÇÃO}

A batata é um dos alimentos mais consumidos no mundo, no entanto, seu consumo no Brasil é baixo (15 kg hab $\left.\mathrm{kno}^{-1}\right)$. Cerca de $95 \%$ desse consumo é na forma não industrializada (NAGANO, 1999), apenas o restante é processado industrialmente. O Brasil deverá manter em expansão o consumo de batata industrializada, a previsão é que em dez anos o sudeste brasileiro duplicará seu consumo, contando, para tanto, com a diversificação e redução nos custos dos produtos derivados da batata (AGRIANUAL, 1997).

A produção brasileira de batata, em 2004, foi de 2.897,87 tem 146.963 ha, com rendimento médio de 19,72 $\mathrm{t} \mathrm{ha}^{-1}$. Minas Gerais, maior produtor do Brasil, contribuiu com $34 \%$ da produção nacional (986.034 t), numa área de 39.387 ha, portanto, com produtividade média de $25 \mathrm{t} \mathrm{ha}^{-1}$ (AGRIANUAL, 2004). No entanto, o crescimento da safra de inverno e a inclusão de áreas de plantio, como as regiões do Triângulo, Alto Paranaíba e Alto São Francisco em Minas Gerais, têm permitido o uso de tecnologias mais avançadas e obtenção de produtividade superior a $40 \mathrm{t} \mathrm{ha}^{-1}$, ou seja, igual à obtida nos principais países produtores europeus (JULIATTI et al., 2001).

Solos de regiões tropicais sob condições de alta precipitação, como os da região do cerrado brasileiro, caracterizam-se em geral, pelos baixos teores de nutrientes disponíveis às plantas. Apresentam baixo teor de boro, independente do material de origem, devido, entre outros aspectos, à alta mobilidade do elemento e ao alto grau de intemperismo do solo (MALAVOLTA, 1980). Além disso, a

${ }^{1}$ Parte da Tese de Doutorado do primeiro autor, apresentada ao Departamento de Fitotecnia da UFLA.

${ }^{2}$ Pesquisador da Empresa de Pesquisa Agropecuária de Minas Gerais - EPAMIG/CTSM - Campus Universitário da Universidade Federal de Lavras/UFLA - Cx. P. 176 - 37200-000 - Lavras, MG - adelande@epamig.ufla.br; epamig@ufla.br

3Professor da Universidade Federal de Lavras/UFLA - Campus Universitário - Cx. P. 3037 -37200-000 - Lavras, MG - marcoalvarenga@ufla.br; janicegc@ufla.br

4Professor da Universidade Federal do Piauí - Campus da Socopo - 64049-550 - Teresina, PI - jnobrega@ufpi.br 
maior remoção pelas colheitas, o uso crescente de calcário e adubos fosfatados também podem contribuir para a redução do nutriente disponível às plantas. A deficiência de boro em batata foi constatada e comprovada experimentalmente no Brasil e correções com este micronutriente promoveram aumentos na produtividade (FILGUEIRA, 1993).

O boro é considerado essencial para a germinação dos grãos de pólen, crescimento do tubo polínico, integridade e funcionamento das membranas celulares. Também desempenha importante papel na migração e metabolismo de carboidratos, facilitando o transporte de açúcares através das membranas na forma do complexo açúcar-borato (MALAVOLTA, 1980; MALAVOLTA et al., 1997; MARSCHNNER, 1995). Apesar da importância para a qualidade dos tubérculos, o seu efeito na cultura da batata tem sido pouco estudado (MONDY \& MUNHI, 1993; ROBERTS \& RHEE, 1990).

Com o advento da expansão da cultura em Minas Gerais em solos com baixo teor de boro, o presente trabalho foi desenvolvido com o objetivo de avaliar a produtividade e qualidade dos tubérculos de duas cultivares de batata em dois solos típicos do cerrado mineiro em função da aplicação de boro.

\section{MATERIAL E MÉTODOS}

O trabalho foi conduzido em casa-de-vegetação do Departamento de Ciência do Solo da Universidade Federal de Lavras (UFLA). Um Latossolo Vermelho (LV) da região de Lavras - MG e um Cambissolo (CX) da região de Itumirim - Minas Gerais, foram utilizados no estudo por representarem solos típicos do cerrado mineiro sob expansão da cultura da batata. Os solos foram coletados na camada superficial ( 0 - 0,20 m de profundidade) de áreas ainda não cultivadas. Parte das amostras de solos foram destorroadas, secas ao ar e passadas em peneiras de $5 \mathrm{~mm}$ e utilizados para enchimento dos vasos com capacidade de $10 \mathrm{dm}^{3}$ e a outra parte foi passada em peneira de $2 \mathrm{~mm}$ (TFSA) para caracterização química e física (Tabela 1). As análises de caracterização dos solos foram feitas segundo metodologia proposta por Embrapa (1997).

$\mathrm{O}$ delineamento experimental foi em blocos casualizados em esquema fatorial 4 x 2 com três repetições. Os fatores estudados foram: doses de boro $(0,0 ; 0,75 ; 1,50$ e 3,0 $\mathrm{mg} \mathrm{dm}^{-3}$ ) e cultivares de batata (Asterix e Monalisa), em cada classe de solo. A cultivar Asterix tem teor de massa seca alta a muito alta, excelente qualidade culinária, é bastante consistente e de cor firme quando cozida. É especialmente indicada para fritura na forma de palha e palitos. A cultivar Monalisa também tem boa qualidade culinária, consistência e cor firme quando cozida, no entanto, não é indicada para fritura, mas para massas, forno e cozimento (NETHERLANDS CATALOGUE OF POTATO VARIETIES, 2003).

A correção dos solos foi realizada com $\mathrm{Ca} \mathrm{CO}_{3}: \mathrm{Mg}$ $\mathrm{CO}_{3}(4: 1)$ (puro para análise) para elevar a saturação de bases a 60\% segundo Fontes (1997). A adubação básica de plantio e cobertura foi realizada segundo Malavolta (1980) para adubação em vasos: $3.800 \mathrm{mg}$ de N; $3.500 \mathrm{mg}$ de P; $4.000 \mathrm{mg}$ de $\mathrm{K} ; 300 \mathrm{mg}$ de $\mathrm{Mg} ; 15 \mathrm{mg}$ de $\mathrm{Cu} ; 50 \mathrm{mg}$ de $\mathrm{Zn} ; 1,0 \mathrm{mg}$ de Mo e 3,0 g de $\mathrm{S}$ adicionado pelo sulfato de amônio e sulfato de magnésio. As fontes utilizadas foram sais puros para análise de $\left(\mathrm{H}_{3} \mathrm{BO}_{3}\right) ; \mathrm{NH}_{4} \mathrm{H}_{2} \mathrm{PO}_{4} ;\left(\mathrm{NH}_{4}\right)_{2} \mathrm{SO}_{4}$; $\mathrm{CuSO}_{4} .5 \mathrm{H}_{2} \mathrm{O} ; \mathrm{ZnSO}_{4} .7 \mathrm{H}_{2} \mathrm{O} ;\left(\mathrm{NH}_{4}\right)_{6} \mathrm{Mo}_{7} \mathrm{O}_{24} \cdot 4 \mathrm{H}_{2} \mathrm{O}$; $\mathrm{MgSO}_{4} \cdot 7 \mathrm{H}_{2} \mathrm{O} ; \mathrm{KCl}$ e $\left(\mathrm{NH}_{2}\right)_{2} \mathrm{CO}$. As doses de $\mathrm{Ne} \mathrm{K}$ foram aplicadas $20 \%$ no plantio e $80 \%$ em cobertura aos 25,35 e 45 dias após o plantio. Todos os nutrientes foram aplicados via líquida, após homogeneização.

TABELA 1 - Atributos químicos e físicos do Latossolo Vermelho (LV) oriundo da região de Lavras - MG e do Cambissolo (CX) da região de Itumirim - MG.

\begin{tabular}{|c|c|c|c|c|c|c|c|c|c|c|c|c|c|}
\hline Solo & pH $\left(\mathrm{H}_{2} \mathrm{O}\right)$ & $\mathbf{P}$ & $\mathbf{K}^{+}$ & $\mathrm{Na}^{+}$ & $\mathrm{Ca}^{2+}$ & $\mathrm{Mg}^{2+}$ & $\mathbf{A l}^{3+}$ & $\mathbf{H}+\mathbf{A l}$ & SB & $\mathbf{t}$ & $\mathbf{T}$ & $\mathbf{m}$ & $\mathbf{V}$ \\
\hline & & \multicolumn{2}{|c|}{$\mathrm{mg} / \mathrm{dm}^{3}$} & \multicolumn{8}{|c|}{ 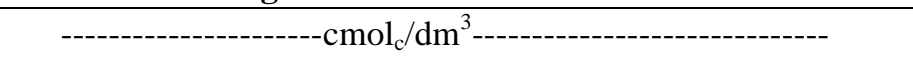 } & \multicolumn{2}{|c|}{$---\%---$} \\
\hline $\mathrm{LV}$ & 4,9 & 1,2 & 13 & 0,0 & 0,7 & 0,2 & 0,9 & 7,0 & 0,9 & 1,8 & 7,9 & 49 & 11,7 \\
\hline \multirow[t]{4}{*}{$\mathrm{Cx}$} & 5,3 & 1,4 & 25 & 1,8 & 0,7 & 0,2 & 0,5 & 2,3 & 1,0 & 1,5 & 3,3 & 34 & 29,7 \\
\hline & & & & & & & & & & & & & \\
\hline & MO & B & $\mathrm{Cu}$ & Mn & $\mathbf{Z n}$ & $\mathbf{F e}$ & $\mathbf{S}$ & Areia & Silte & Argila & \multicolumn{3}{|c|}{ Retenção $\mathrm{H}_{2} \mathrm{O}$} \\
\hline & dag $\mathrm{kg}^{-1}$ & \multicolumn{6}{|c|}{ 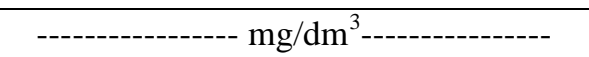 } & \multicolumn{3}{|c|}{------- dag kg ${ }^{-1}$------- } & $15 \mathrm{Atm}$ & \multicolumn{2}{|c|}{$0,33 \mathrm{Atm}$} \\
\hline LV & 3,0 & 0,4 & 1,5 & 4,8 & 1,2 & 47,3 & 8,9 & 21 & 11 & 68 & 20,72 & \multicolumn{2}{|c|}{20,9} \\
\hline $\mathrm{Cx}$ & 1,3 & 0,3 & 0,8 & 3,7 & 1,1 & 31,7 & 8,0 & 33 & 48 & 19 & 7,44 & \multicolumn{2}{|c|}{8,22} \\
\hline
\end{tabular}

Ciênc. agrotec., Lavras, v. 31, n. 2, p. 385-392, mar./abr., 2007 
O plantio foi realizado com um tubérculo-semente com peso médio de $50 \mathrm{~g}$ em vasos, preenchidos com $2 / 3 \mathrm{da}$ sua capacidade e o restante do solo reservado para posterior operação de amontoa. A irrigação foi realizada com água deionizada, em volume calculado de acordo com a capacidade de retenção de água dos solos (Tabela 1), através das curvas de capacidade de campo, em acordo com a época e idade da cultura. O peso dos vasos foi controlado semanalmente e a umidade mantida em torno de $60 \%$ do volume total de poros.

Os demais tratos culturais e fitossanitários foram realizados de acordo com a necessidade e idade da planta. Ao final do ciclo da cultura, os tubérculos foram pesados para avaliação da produção por vaso e posteriormente, foram analisadas as principais características químicas responsáveis pela qualidade da batata (teor de massa seca dos tubérculos (\%), amido (\%), açúcares redutores (\%) e açúcares totais (\%). A avaliação da produção foi feita após a seleção dos tubérculos por vaso.

A determinação da massa seca dos tubérculos foi realizada gravimetricamente com secagem da amostra em estufa com aeração forçada e temperatura controlada a $65^{\circ} \mathrm{C}$, por 48 horas, obtendo-se assim a pré-secagem do material para posterior secagem definitiva em estufa com temperatura controlada a $105^{\circ} \mathrm{C}$ até peso constante (SILVA, 1990). O teor de amido foi determinado pelo método de extração por hidrólise ácida, segundo a técnica da Association of official analytical chemists - AOAC (1970) e identificado pelo método de Somogy, modificado por Nelson (1944). Os teores de açúcares redutores e açúcares totais foram determinados pelo método de extração de Enyon, citado por AOAC (1970) e identificados pelo método redutométrico de Somogy-Nelson (SOUTHGATE, 1991).

Todas as variáveis foram submetidas à análise de variância e foram ajustadas as equações de regressão.

\section{RESULTADOS E DISCUSSÃO}

\section{Produção de tubérculos}

Os tratamentos, doses de boro e cultivares, influenciaram a produtividade de tubérculos conforme interação verificada no LV (Figura 1) e CX (Figura 2). Em ambos os solos, modelos quadráticos foram estabelecidos.

No LV (Figura 1) a produtividade máxima estimada para a cultivar Asterix foi de 559,82 g/vaso de tubérculos com 2,19 $\mathrm{mg} \mathrm{dm}^{-3}$ de boro e para a Monalisa a produtividade máxima estimada foi de 552,57 g/vaso de tubérculos, obtida com 1,59 $\mathrm{mg} \mathrm{dm}^{-3}$ de boro. No CX (Figura 2), as produtividades máximas estimadas foram de 367,29 e 176,02 $\mathrm{g}$ /vaso de tubérculos com 2,22 e 1,62 $\mathrm{mg} \mathrm{dm}^{-3}$ de boro para as cultivares Asterix e Monalisa, respectivamente.

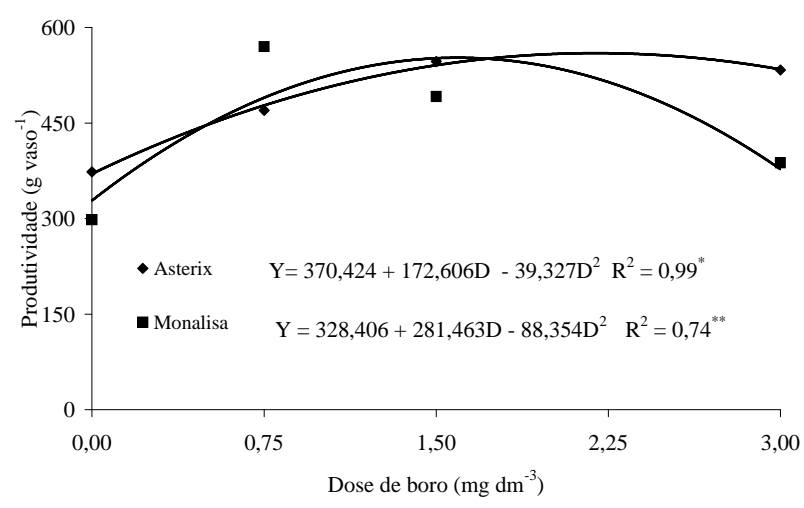

FIGURA 1 - Produtividade de tubérculos de batata das cultivares Asterix e Monalisa em função de doses de boro em Latossolo vermelho.

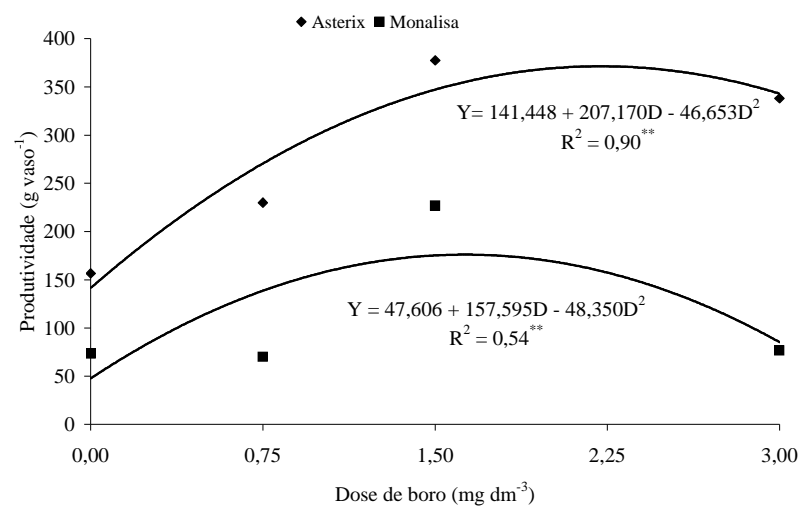

FIGURA 2 - Produtividade de tubérculos de batata das cultivares Asterix e Monalisa em função de doses de boro em Cambissolo.

Observa-se que no $\mathrm{CX}$ as produtividades foram menores quando comparadas às obtidas no LV e que a queda da produtividade foi maior para a cultivar Monalisa.

No presente estudo, a menor produção de tubérculos no $\mathrm{CX}$ decorre provavelmente do encrostamento verificado na camada superficial de aproximadamente $2 \mathrm{~cm}$, formando uma camada dura e impermeável dificultando a infiltração de água, o desenvolvimento da parte aérea e afetando a expansão e produção dos tubérculos de batata. Segundo Almeida \& 
Rezende (1985), os Cambissolos, além de serem muito instáveis, apresentam facilidade de encrostamento provocada pelos elevados índices de silte, conforme verificado no solo em estudo (Tabela 1).

$\mathrm{O}$ aumento da produtividade em resposta ao boro aplicado, ocorreu em função dos baixos teores deste nutriente nos solos utilizados, comparados à faixa considerada crítica por Alvarez-Venegas et al. (1999) de 0,36 a $0,60 \mathrm{mg} \mathrm{dm}^{-3}$ extraído por água quente para o desenvolvimento das culturas em geral.

Sacramento et al. (1979), ao estudar o efeito de doses de boro em solos da Zona da Mata de Minas Gerais, também verificaram aumento de $35 \%$ na produtividade de tubérculos de batata com a dose de $26 \mathrm{~kg} \mathrm{ha}^{-1}$ de boro (1,43 $\mathrm{mg} \mathrm{dm}^{-3}$ de boro). Comportamento semelhante foi também verificado por Pregno \& Armour (1992) que constataram aumentos na produtividade e produção de maior número de tubérculos graúdos (> $80 \mathrm{~g}$ ) com aplicação de 2,0 $\mathrm{kg} \mathrm{ha}^{-1}$ de boro, elevando a produtividade de $19,7 \mathrm{t} \mathrm{ha}^{-1}$ para $27,3 \mathrm{t} \mathrm{ha}^{-1}$.

\section{Massa seca, amido, açúcares redutores e açúcares totais} nos tubérculos

No LV (Figura 3), a aplicação de boro influenciou a produção de massa seca (MS) nos tubérculos da cultivar Asterix ajustando-se um modelo quadrático, sendo o teor máximo estimado $(15,75 \%)$ obtido com $1,49 \mathrm{mg} \mathrm{dm}^{-3} \mathrm{de}$ boro. No CX (Figura 4), o ajuste foi linear, para a mesma cultivar (Asterix), ou seja, houve resposta do aumento na dose de boro.

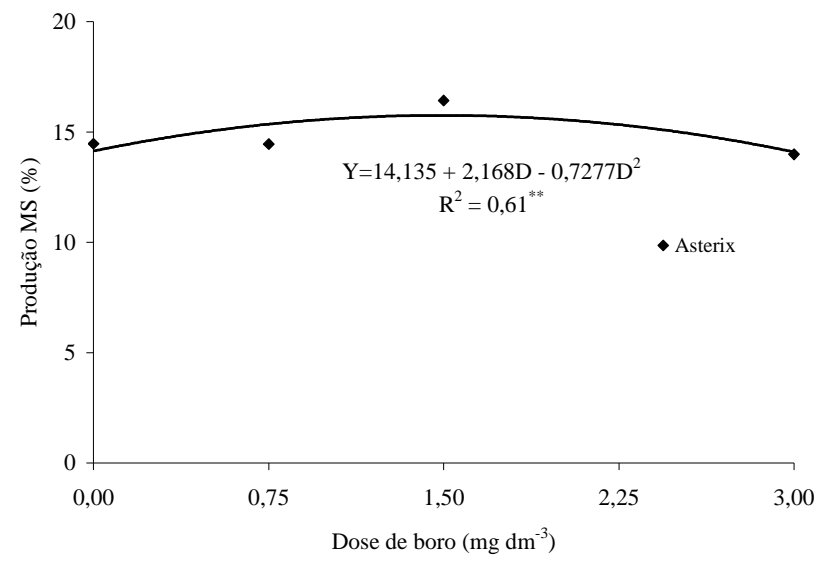

FIGURA 3 - Produção de massa seca em tubérculos de batata cultivar Asterix, em função de doses de boro em Latossolo vermelho.

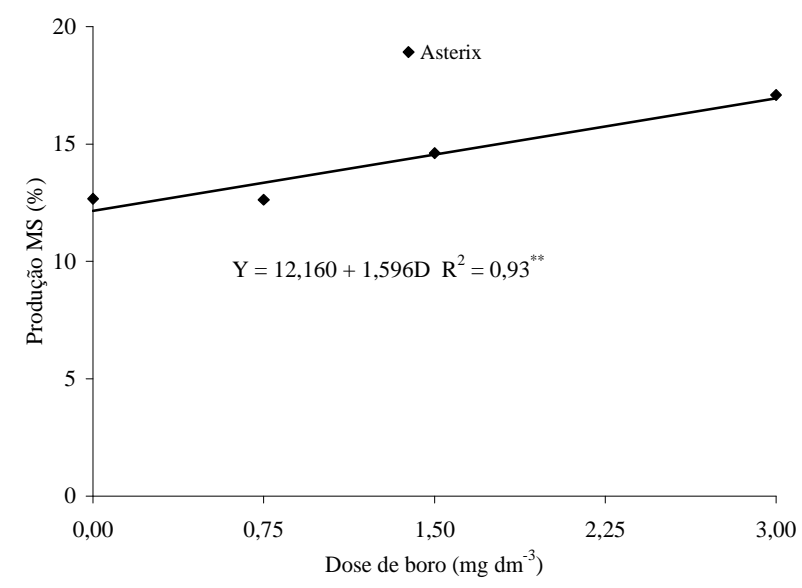

FIGURA 4 - Produção de massa seca em tubérculos de batata cultivar Asterix, em função de doses de boro em Cambissolo.

O maior desenvolvimento foliar, aliado às condições de alta temperatura no ambiente, podem ter influenciado os teores de massa seca dos tubérculos, principalmente da cultivar Asterix, que apresenta como principal característica genética, teores médios de massa seca nos tubérculos.

Em ambos os solos, os valores encontrados para produção de massa seca nos tubérculos foram semelhantes aos obtidos por Coelho (1998) para as cultivares Baraka $(16,43 \%)$ e Achat $(13,46 \%)$.

A porcentagem de amido nos tubérculos também foi influenciada pelos tratamentos e no LV (Figura 5), ajustou-se um modelo quadrático para ambas cultivares. Na cultivar Asterix, a dose de $1,46 \mathrm{mg} \mathrm{dm}^{-3}$ de boro propiciou o teor máximo estimado de amido $(8,92 \%)$ na massa fresca e, na cultivar Monalisa a dose de $1,58 \mathrm{mg}$ $\mathrm{dm}^{-3}$ de boro propiciou $8,07 \%$ de amido na massa fresca. No CX (Figura 6), o efeito do boro sobre os teores de amido na massa fresca dos tubérculos mostrou-se variável, foi verificado redução linear no teor de amido para a cultivar Asterix e de efeito quadrático para a cultivar Monalisa, com ponto de máximo estimado de $8,75 \%$ na dose de 2,71 $\mathrm{mg} \mathrm{dm}^{-3}$ de boro.

Segundo Borgsttron (1976), os teores de amido na massa fresca de tubérculos de batata podem variar de 9 a $18 \%$ com média entre 12 e $13 \%$. Os valores encontrados em ambos os solos foram menores que os relatados pelo autor, porém próximos dos encontrados por Coelho (1998) para as cultivares Baraka (10,24\%) e Achat $(8,33 \%)$. 


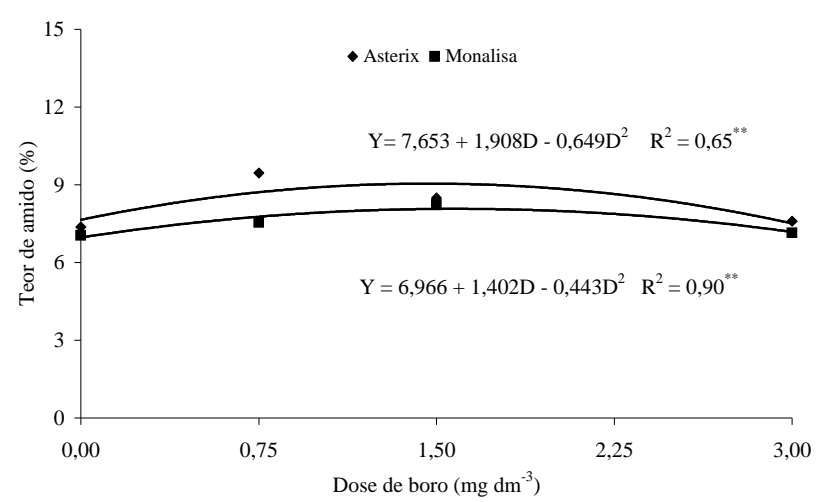

FIGURA 5 - Teor de amido em tubérculos de batata nas cultivares Asterix e Monalisa em função de doses de boro em Latossolo vermelho.

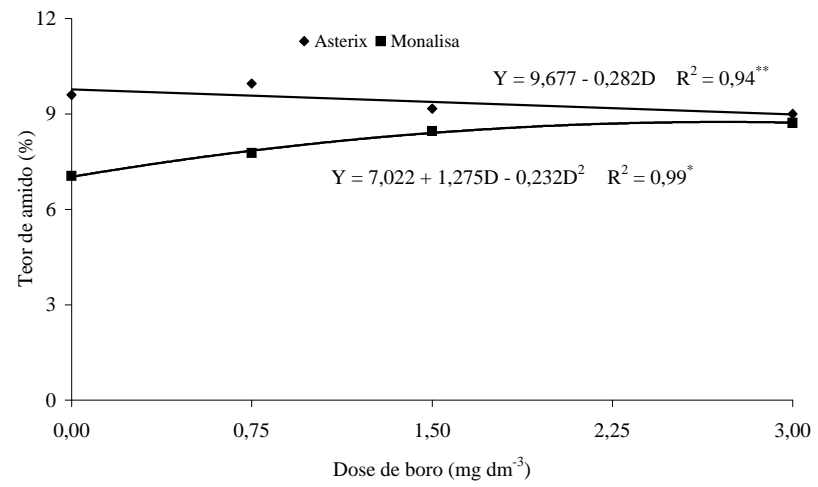

FIGURA 6 - Teor de amido em tubérculos de batata nas cultivares Asterix e Monalisa em função de doses de boro em Cambissolo.

A cultivar Asterix apresentou maiores teores de amido em ambos os solos quando comparada a Monalisa, contudo no CX houve um ajuste linear decrescente, provavelmente, devido ao efeito de diluição pela maior produtividade de tubérculos desta cultivar. O maior desenvolvimento foliar aliado às condições de alta temperatura na casa-de-vegetação (estresse térmico), podem ter contribuído para a redução dos teores de amido e massa seca. $\mathrm{O}$ estresse térmico diminui os fotoassimilados disponíveis no desenvolvimento da planta e partição nos tubérculos (DAM et al., 1996; PRANGE et al., 1990), e reduz a translocação dos fotoassimilados para os tubérculos (HUGHES, 1974; MARINUS \& BLODAENDER, 1975).

Para os teores de açúcares redutores foi também verificada interação entre doses de boro e cultivares tanto no LV (Figura 7) como no CX (Figura 8). No LV, as cultivares Asterix e a Monalisa foram ajustadas a um modelo linear decrescente, ou seja, de redução nos teores de açúcares redutores com o aumento das doses de boro.

No CX, o efeito do boro sobre os teores de açúcares redutores ocorreu de forma diferenciada. Embora as variedades tenham se ajustado a um modelo quadrático, a Asterix, na dose 2,32 $\mathrm{mg} \mathrm{dm}^{-3}$ de boro, apresentou teor mínimo estimado de $0,17 \%$ enquanto a Monalisa, na dose $1,18 \mathrm{mg} \mathrm{dm}^{-3}$, teor máximo estimado de $0,24 \%$.

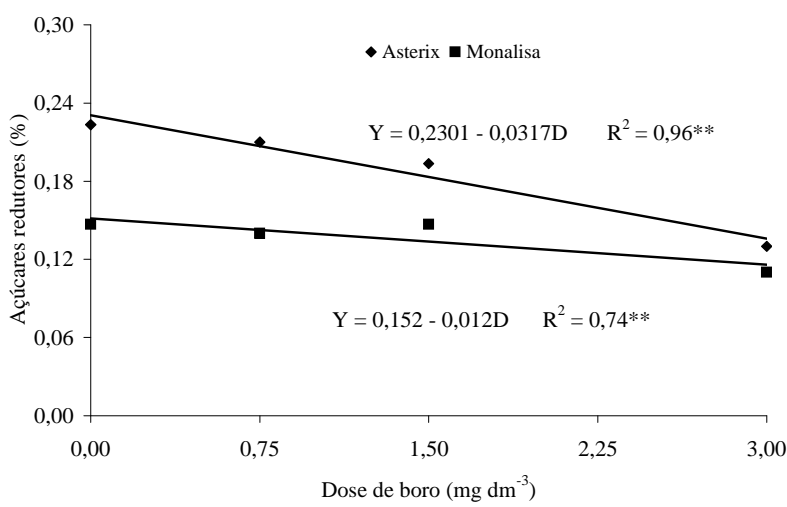

FIGURA 7 - Teor de açúcares redutores em tubérculos de batata nas cultivares Asterix e Monalisa em função de doses de boro em Latossolo vermelho.

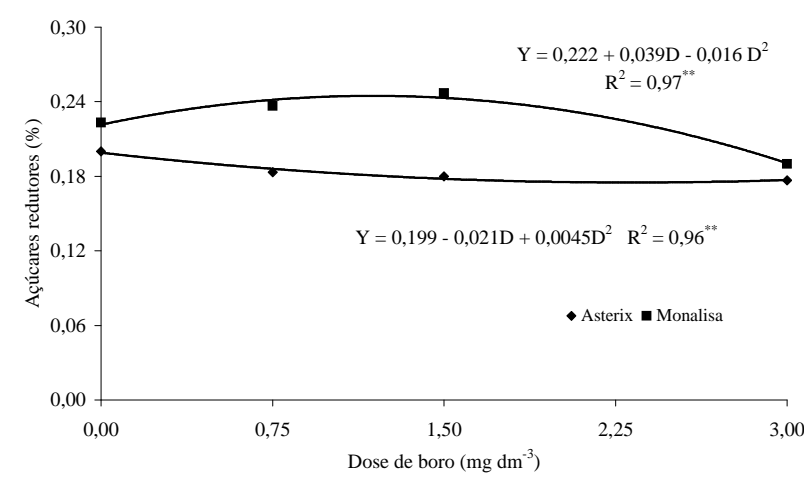

FIGURA 8 - Teor de açúcares redutores em tubérculos de batata nas cultivares Asterix e Monalisa em função de doses de boro em Cambissolo. 
Os teores encontrados de açúcares redutores para a Monalisa e Asterix são considerados adequados de acordo com Carvalho et al. (1997), e segundo Nelson et al. (1998) o teor ideal em massa fresca do tubérculo é de 0,20\%. Os valores encontrados foram semelhantes aos obtidos por Coelho (1998), de 0,16\% para a cultivar Achat e de 0,16\% para a cultivar Baraka, porém menores que os encontrados por Pereira \& Campos (1999) em trabalho de melhoramento genético de batata. Esses autores, avaliando níveis de açúcares redutores em genótipos de batata, encontraram valores variando de $0,21 \%$ a $1,71 \%$ nos clones e de $0,34 \%$ a $0,31 \%$ nas cultivares Bintje e Atlantic, respectivamente.

Para os teores de açúcares totais foi verificada interação entre doses de boro e cultivares em ambos os solos (Figura 9 e 10, respectivamente para o LV e CX).

No LV (Figura 9), houve redução dos teores de açúcares totais nos tubérculos com o aumento da dose de boro tanto para a cultivar Asterix quanto para a Monalisa.

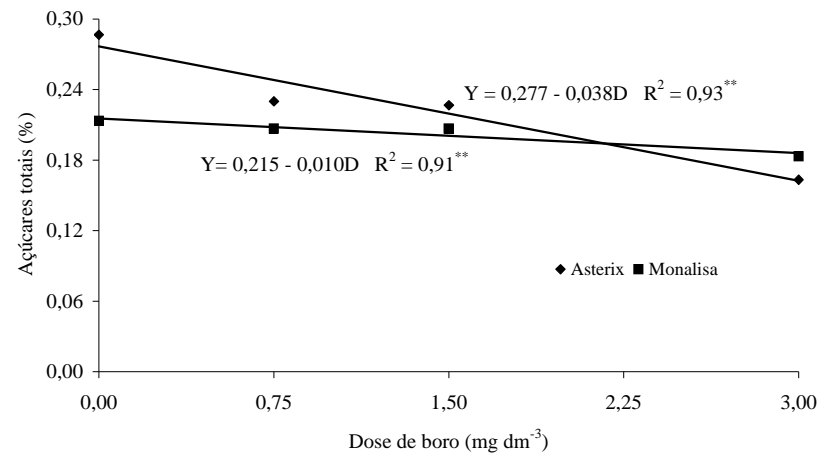

FIGURA 9 - Teor de açúcares totais em tubérculos de batata nas cultivares Asterix e Monalisa em função de doses de boro em Latossolo vermelho.

No CX, (Figura 10) a cultivar Asterix ajustou-se a um modelo linear positivo, ou seja, houve aumento nos teores de açúcares totais com o aumento das doses de boro, enquanto a Monalisa apresentou um comportamento quadrático com ponto de teor máximo estimado de $0,30 \%$ na dose $1,44 \mathrm{mg} \mathrm{dm}^{-3}$ de boro.

Embora tenha ocorrido um comportamento diferenciado entre os solos nos teores de açúcares totais, os valores encontrados estão dentro da faixa de normalidade e são semelhantes aos encontrados por Coelho (1998), para as cultivares Baraka $(0,23 \%)$ e Achat $(0,29 \%)$.

A concentração de açúcares varia durante o crescimento, principalmente se algum estresse ambiental ou cultural atrasar a maturidade química. Os tubérculos podem estar fisicamente maduros sem, no entanto terem adquirido a maturidade química, portanto, apresentando baixa concentração de açúcares (DAM et al., 1996; PRANGE et al., 1990).

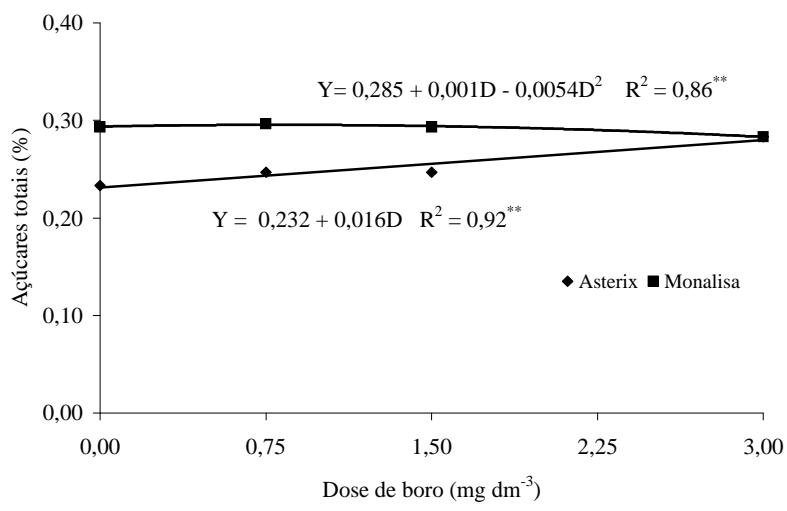

FIGURA 10 - Teor de açúcares totais em tubérculos de batata nas cultivares Asterix e Monalisa em função de doses de boro em Cambissolo.

No presente trabalho, as condições de altas temperaturas no ambiente de casa-de-vegetação podem ter provocado estresse. Os aspectos discutidos anteriormente mostram que a adubação com boro influencia tanto a produção de tubérculos quanto às características que definem a qualidade dos mesmos. No entanto, esse efeito ocorre de forma diferenciada, conforme a cultivar e tipo de solo, fato que deve ser levado em consideração no programa de fertilidade do solo para o cultivo de batata.

\section{CONCLUSÕES}

Entre os solos, a maior produção de tubérculos, independentemente da cultivar e dose de boro, ocorre no $\mathrm{LV}$, provavelmente devido ao alto teor de silte no $\mathrm{CX}$, que promove o encrostamento da superfície do solo e dificulta a penetração de água e formação dos tubérculos;

No LV, a produtividade máxima estimada de tubérculos foi semelhante entre as cultivares, embora a exigência em boro para produtividade máxima pela Monalisa seja menor que para Asterix;

No CX, a cultivar Asterix foi mais produtiva (108\%), embora seja também mais exigente em boro $(37 \%)$ que a Monalisa. 
No LV, a cultivar Asterix apresentou $10 \%$ a mais de amido que a Monalisa, com $0,12 \mathrm{mg} \mathrm{dm}^{-3}$ de boro a menos na adubação, evidenciando maior conversão de nutrientes em fotoassimilados. No CX, a cultivar Asterix apesar de apresentar teor mais alto de amido apresentou decréscimo com o aumento do boro;

No LV, os teores de açúcares redutores decresceram com o incremento das doses de boro nas duas cultivares (Asterix e Monalisa). No CX, apresentaram comportamento diferente, sendo que a cultivar Monalisa apresentou ponto de máximo teor e a Asterix teor mínimo.

\section{REFERÊNCIAS BIBLIOGRÁFICAS}

AGRIANUAl. Anuário estatístico da agricultura brasileira. São Paulo: FNP Consultoria \& Comércio, 1997.

AGRIAnUAL. Anuário estatístico da agricultura brasileira. São Paulo: FNP Consultoria \& Comércio, 2004

ALMEIDA, J. R.; REZENDE, M. Considerações sobre o manejo de solos rasos desenvolvidos de rochas pelíticas no Estado de Minas Gerais. Informe Agropecuário, Belo Horizonte, v. 11, n. 128, p. 19-26, ago. 1985.

ALVAREZ-VENEGAS, V. H.; NOVAIS, R. F. de; BARROS, N. F. de; CANTARUTTI, R. B.; LOPES, A. S. Interpretação dos resultados das análises de solos. In: COMISSÃO DE FERTILIDADE DE SOLOS DE Minas Gerais. Recomendações para o uso de corretivos e fertilizantes em Minas Gerais: $5^{\text {a }}$ aproximação. Lavras, 1999. p. 25-32.

ASSOCIATION OF OFFICIAL ANALYTICAL CHEMISTS Official methods of analysis. 11. ed. Washington, 1970. $1015 \mathrm{p}$.

BORGSTTRON, G. Principles of food science. 2. ed. Wesport: Food Nutrition, 1976. v. 1, 397 p.

CARVALHO, R.; TRAVAGLINI, D. A.; MATSURA, P. T.; CABRAL, A. C. D.; MORI, E. E. M. Comportamento das variedades Bintje e Radosa na obtenção de flocos de batatinha e fritas do tipo "chips". Boletim do Instituto de Tecnologia de Alimentos, Campinas, v. 54, p. 135-152, nov./dez. 1997.

COELHO, A. H. R. Alterações químicas e qualidade de fritura de duas cultivares de batata (Solanum tuberosum L.) armazenadas em atmosfera modificada em temperatura ambiente e sob refrigeração. 1998. 145 p. Tese (Doutorado) - Universidade Federal de Lavras, Lavras, 1998.
DAM, J. van; KOOMAN, P. L.; STRUIK, P. C. Effects of temperature and photoperiod an early growth and final number of tuber in potato (Solanum tuberosum L.). Potato Research, Wageningen, v. 39, n. 1, p. 51-62, 1996.

EMPRESA BRASILEIRA DE PESQUISA AGROPECUÁRIA. Centro Nacional de Pesquisa de Solos. Manual de métodos de análises de solo. 2. ed. Rio de Janeiro: CNPS, 1997. 212 p.

FILGUEIRA, F. A. R. Nutrição mineral e adubação em bataticultura, no centro sul. In: FERREIRA, M. E.; CASTELLANE, P. D.; CRUZ, M. C. P. da (Eds.). Nutrição e adubação de hortaliças. Piracicaba: POTAFÓS, 1993.p. 402428.

FONTES, P. C. R. Preparo do solo nutrição mineral e adubação da batateira. Viçosa: UFV, 1997. 42 p. (Cadernos didáticos, 3 ).

HUGHES, J. C. Factors influencing the quality of ware potatoes: environmental factors. Potato Research, Wageningen, v. 17, n. 31, p. 512-547, 1974.

JULIATTI, F. C.; LUZ, J. M. Q.; BRACÉELOS, J. E. T. Batata no triângulo mineiro. Batata Show, [S.1.], v. 1, n. 3, p. 28-30, set. 2001 .

MALAVOLTA, E. Elementos de nutrição mineral de plantas. São Paulo: Agronômica Ceres, 1980. 215 p.

MALAVOLTA, E.; VITTI, G. C.; OLIVEIRA, S. A. Avaliação do estado nutricional das plantas: princípios e aplicações. Piracicaba: Associação Brasileira para Pesquisa da Potassa e do Fosfato, 1997. 210 p.

MARINUS, J.; BLODAENDER, K. B. A. Response of some potato varieties to temperature. Potato Research, Wageningen, v. 18, p. 189-201, 1975.

MARSCHNER, H. Mineral nutrition of higher plants. San Diego: Academic, 1995. 889 p.

MONDY, N. I.; MUNHI, C. B. Effect of boron on enzymatic discolaration and phenolic and ascorbic acid contend of potatoes. Journal of Agricultural Food Chemistry, Washington, v. 41, n. 4, p. 554-556, Apr. 1993. 
NAGANO, Y. Batata brasileira tem qualidade. Informe Agropecuário, Belo horizonte, v. 20, n. 197, p. 1-2, 1999.

NELSON, D. G.; JENKINS, P. D.; GILLISON, T. C. Processing potencial of potato cultivars at early harvests. Potato Research, Wageningen, v. 31, n. 4, p. 633-642, Dec. 1998.

NELSON, N. A. A photometric adaptation of Somogy method for determination of glucose. Journal of Biological Chemistry, Baltimore, v. 153, p. 375-390, 1944.

NETHERLANDS CATALOGUE OF POTATO VARIETIES. NIVAA Haia. Wageningen, 2003.

PEREIRA, A. S.; CAMPOS, A. Teor de açúcar em genótipos de batata (Solanum tuberosum L.). Ciência Rural, [S.1.], v. 29, n. 1, 1999.

PRANGE, R. K.; MCRAE, K. B.; MIDMORE, D. J.; DENG, R. Reduction in potato growth at high temperature: role of photosyntesis and dark respiration. American Potato Journal, Orono, v. 67, n. 6, p. 357-369, June 1990.
PREGNO, L. M.; ARMOUR, J. D. Boron deficiency and toxicity in potato cv. Sebago on oxisol of the Athert Tablelands, North Queensland. Australian Journal of Experimental Agriculture, Collingwood, v. 32, n. 2, p. 251253, Sept. 1992.

ROBERTS, S.; RHEE, J. K. Boron utilization by potato in nutrient cultures and in field plantings. Communications in Soil Science in Plant Analysis, New York, v. 21, n. 11/ 12, p. 921-932, 1990.

SACRAMENTO, C. K.; MONNERAT, P. H.; MIZUBUTI, A.; CAMPOS, J. P.; CARDOSO, A. A.; COELHO, J. P. Respostas de cultivares de batata (Solanum tuberosum L.) à adubação com bórax. In: CONGRESSO BRASILEIRO DE OLERICULTURA, 19., 1979, Florianópolis, SC. Anais... Florianópolis: Empresa Catarinense de Pesquisa Agropecuária, 1979. v. 2, p. 226-227.

SILVA, D. J. Análise de alimentos: métodos químicos e biológicos. 2. ed. Viçosa: UFV, 1990. 165 p.

SOUTHGATE, D. A. T. Determination of foods carbohydrates. London: Elservier Applied Science, 1991. 232 p. 